\title{
PENGARUH KEPERCAYAAN DAN KOMITMEN TERHADAP RANTAI PASOKAN YANG DIMEDIASI OLEH KETERHUBUNGAN PEMASOK PADA PEMILIK TOKO KELONTONG DI DKI JAKARTA
}

\author{
Andreas Wijaya \\ Fakultas Ilmu Sosial dan Humaniora, Universitas Bunda Mulia \\ email: awijaya@bundamulia.ac.id
}

\begin{abstract}
This study aims to determine the effect of trust and commitment in the relationship between the suppliers and the owner of a grocery store in Jakarta. The data was collected through questionnaires and processed using IBM AMOS 24

The data has been collected through questionnaires and processed using IBM AMOS 24 and it can be concluded that trust has an influence on the commitment and supplier relationship, and supplier relationships have an influence on the supply chain, but commitments have no effect on supplier relationships
\end{abstract}

Keywords: Trust, Commitment, Supplier Relationships, Supply Chain

\begin{abstract}
ABSTRAK
Penelitian ini bertujuan untuk mempelajari tentang pengaruh kepercayaan dan komitmen dalam keterhubungan pemasok terhadap rantai pasokan pada pemilik toko kelontong di DKI Jakarta. Data tersebut diolah menggunakan IBM AMOS 24 dari hasil olah tersebut data dapat dilihat kepercayaan memiliki pengaruh terhadap komitmen dan hubungan relasi dengan pemasok, dan keterhubungan pemasok memiliki pengaruh terhadap rantai pasokan, namum komitmen tidak memiliki pengaruh terhadap hubungan relasi dengan pemasok
\end{abstract}

Keywords: Kepercayaan, Komitmen, Keterketerhubungan pemasok, Rantai Pasokan

\section{PENDAHULUAN}

Seiring dengan perkembangan jaman, khususnya untuk ritel modern semakin berkembang dan bertumbuh. Namun kenyataanya untuk binsis ritel tradisional mengalami keadaan yang berbeda dari ritel modern, terlihat semakin mengalami penurunan dibandingkan bisnis ritel modern. Hasil yang dilakukan oleh lembaga survei ( Nielsen 2015) menunjukkan:

Gambar 1 : Grafik pertumbuhan ritel dari tahun 2012 sampai 2014.
Gambar berikut menunjukkan bahwa
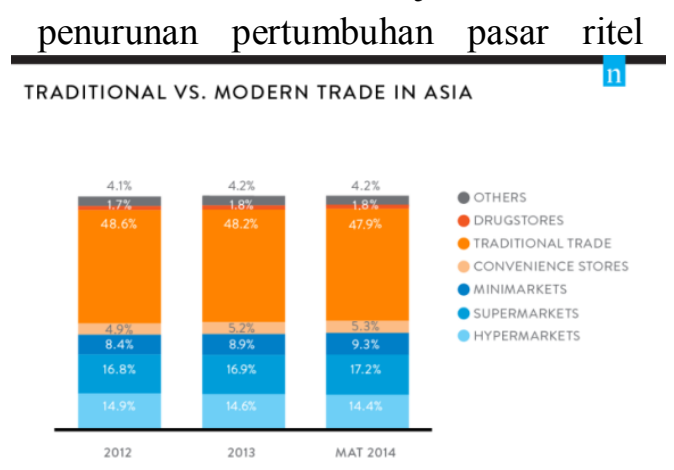
traditional tRADE CONVENIENCE STORES - minimarkets - SUPERMARKETS HYPERMARKETS ang semakin menurun dari tahun 2012 sampai dengan 2014. Melihat hal ini, Komisi Pengawas 
Persaingan Usaha (KPPU) mencatat fakta bahwa keberadaan retailer kecil yang berdekatan dengan toko minimarket modern merasa terancam. Beberapa toko kelontong yang letaknya berdekatan dengan toko ritel modern membuat pelaku ritel tradisional terpengaruh dengan program marketing toko "Diskon Super Hemat" untuk produk tertentu sehingga menyebabkan penurunan omset bagi retailer kecil tersebut. Dikarenakan, memang harga yang dijual kalah saing oleh pelaku bisnis minimarkert modern dan sebagian retailer kecil memang memiliki keterbatasan manajemen, permodalan terutama akses terhadap pasokan barang sehingga tidak dapat bersaing dengan minimarket modern.

Salah satu faktor yang menyebabkan ritel tradisional kalah bersaing dengan ritel modern yaitu, harga produk yang lebih murah yaitu perbedaan model distribusi toko ritel tradisional dan modern. Mata rantai distribusi toko ritel tradisional cenderung lebih panjang sehingga harga dapat menjadi lebih mahal ataupun bila harga di toko ritel moden beformat minimarket lebih mahal, tetap mendapatkan keuntungan dari toko ritel modern berformat supermarket atau hypermarket bahkan grosir karena berasal dari satu perusahaan atau satu modal. Hal ini dapat diilustrasikan pada gambar dibawah ini .
Gambar 2

\section{Model Distribusi Ritel \\ Tradisional}

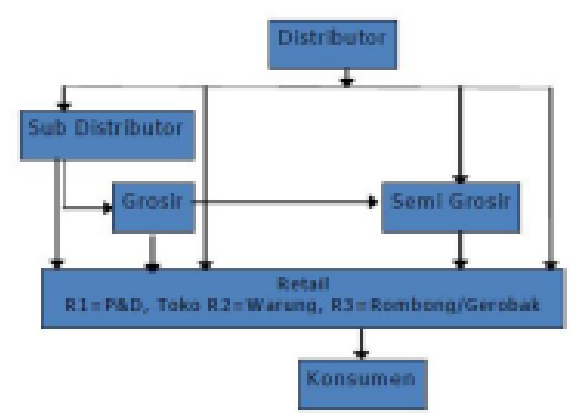

Sumber : KPPU 2010

Gambar 3

Model Distribusi Ritel Modern

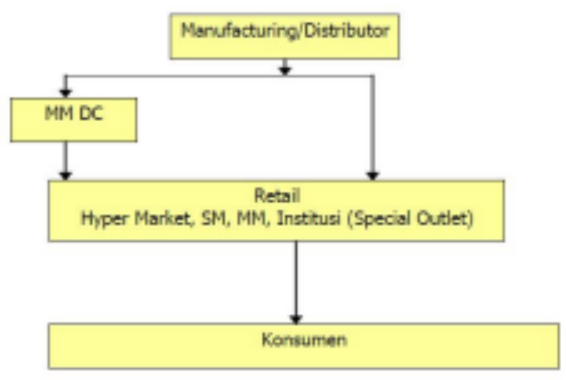

Sumber : KPPU 2010

Selain itu dalam penelitian ini masih terdapat celah penelitian dari penelitian sebelumnya yang dilakukan oleh Garbino \& Johnson (1999), Han et al. (1993), (Morgan dan Hunt 1994), Ruyter dan Wetzels (1999) menunjukkan bahwa kepercayaan merupakan antesedan konstruk komitmen, sedangkan menurut Studi 
Nursatyo (2003), Dwyer et al. (1978), Wilson (1995), Geykenes et al. (1996) menunjukkan bahwa komitmen merupakan antesedan konstruk kepercayaan

Berdasarkan uraian latar belakang yang meliputi fenomena bisnis dan kesenjangan hasil penelitian, maka rumusan masalah yang didapat adalah sebagai berikut :

1. Apakah peubah komitmen berpengaruh positif terhadap keterhubungan pemasok?

2. Apakah peubah kepercayaan berpengaruh positif terhadap keterhubungan pemasok?

3. Apakah peubah kepercayaan berpengaruh positif terhadap komitmen?

4. Apakah peubah keterhubungan pemasok berpengaruh positif terhadap rantai pasokan?

\section{RERANGKA KONSEPTUAL DAN} HIPOTESIS

\section{Pengertian Kepercayaan}

Zulganef (2002) mendefinisikan kepercayaan sebagai keinginan menggantungkan diri pada mitra pertukaran yang dipercayai. Pavlou dan Ba (2002) mendefinisikan kepercayaan sebagai penilaian hubungan seseorang dengan orang lain yang akan melakukan transaksi tertentu sesuai dengan harapan dalam sebuah lingkungan yang penuh ketidakpastian. Moorman (1993) mendefinisikan kepercayaan (sebagai kesediaan individu untuk menggantungkan dirinya pada pihak lain yang terlibat dalam pertukaran karena individu mempunyai keyakinan kepada pihak lain. Ketika satu pihak mempunyai keyakinan bahwa pihak lain yoang terlibat dalam pertukaran mempunyai kehandalan dan integritas, maka dapat dikatakan ada kepercayaan

\section{Indikator Kepercayaan}

Penelitian Garbarino dan Johnson (1999) memberikan rujukan pada penelitian kepercayaan pada pemasok. Indikator yang dipergunakan dalam mengukur kepercayaan pemasok adalah sebagai berikut:

1. Kredibilitas pemasok

2. Kualitas barang yang ditawarkan pemasok

3. Keterbukaan pemasok

\section{Pengertian Komitmen}

Komitmen pemasok merupakan janji, ikrar atau tekad pemasok untuk menjalin hubungan berkelanjutan dengan pembeli (Morgan dan Hunt, 1994). Komitmen pemasok menunjukkan bahwa pemasok menganggap kelanjutan hubungan dengan pembelinya merupakan hal yang harus dijaga dengan baik. Moore (1998) berpendapat bahwa pemasok yang membuktikan komitmennya untuk menjalin hubungan berkelanjutan dengan pembelinya akan menunjukkan bahwa pemasok tersebut tidak bersikap oportunis. Komitmen, seperti halnya dengan kepercayaan juga menyatakan secara langsung dan apa adanya tentang rahasia perusahaan, diluar kepentingan untuk merencanakan penyusunan hubungan, tetapi komitmen menyatakan percaya bahwa mitra pertukaran kerjanya akan bertindak dengan integritas. 


\section{Indikator Komitmen}

Studi Ganesan (1994) memberikan rujukan pada penelitian hubungan jangka panjang dengan pemasok. Indikator yang dipergunakan dalam mengukur hubungan jangka panjang dengan pemasok merujuk pada Cempaka dan Yoestini (2003); adalah sebagai berikut,:

1. Usaha penyalur untuk memelihara hubungan.

2. Keuntungan hubungan jangka panjang

3. Kesamaan tujuan jangka panjang.

\section{Definisi Keterhubungan pemasok}

Pemasok merupakan mitra pertukaran yang penting dalam menunjang strategi perusahaan. Pengolaan pemasok membutuhkan kemampuan negosiasi khusus, karena mereka bukanlah bagian dari negosiasi. Maka dari itu suatu perusahaan harus mempunyai hubungan yang baik dengan pemasok. Menurut Metter dan Rohner (2009), Hubungan dengan pemasok adalah sebuah pendekatan komprehensif untuk mengola interaksi antara organisasi dengan perusahaan yang memasok produk atau jasa yang digunakan di organisasi.

\section{Indikator Keterhubungan pemasok}

Variabel keterhubungan pemasok diadopsi dari penelitian Praharsi dkk. (2014), meliputi :

1. Kualitas produk

2. Pemenuhan pesanan

3. Biaya pengadaan

\section{Pembelajaran}

\section{Definisi Rantai Pasokan}

Levi et al. (2000) mendifinisikan rantai pasokan sebagai suatu pendekatan yang digunakan untuk mencapai pengintegrasian yang efisien dari pemasok, manufaktur, distributor, pengecer, dan pelanggan. Artinya barang diproduksi dalam jumlah yang tepat, pada saat yang tepat, dan pada tempat yang tepat dengan tujuan mencapai suatu biaya dari sistem secara keseluruhan yang minimum dan juga mencapai aras layanan yang diinginkan

\section{Indikator Rantai Pasokan}

Ramdas dan Spekman (2000) dan Simatupang dan Sridharan (2005) menjabarkan tiga kriteria dalam pengukuran kinerja operasi perusahaan pada rantai pasokan yaitu :

\section{Keterpenuhan}

mengidentifikasi sejauh mana perusahaan mampu melakukan pemenuhan permintaan.

\section{Kinerja persediaan} mengidentifikasi sejauh mana perusahaan mampu melakukan pengelolaan persediaan.
3. Ketanggapan
mengidentifikasi sejauh mana perusahaan mampu menanggapi permintaan konsumen. 


\section{SISTEMATIKA PARADIGMA PENELITIAN}

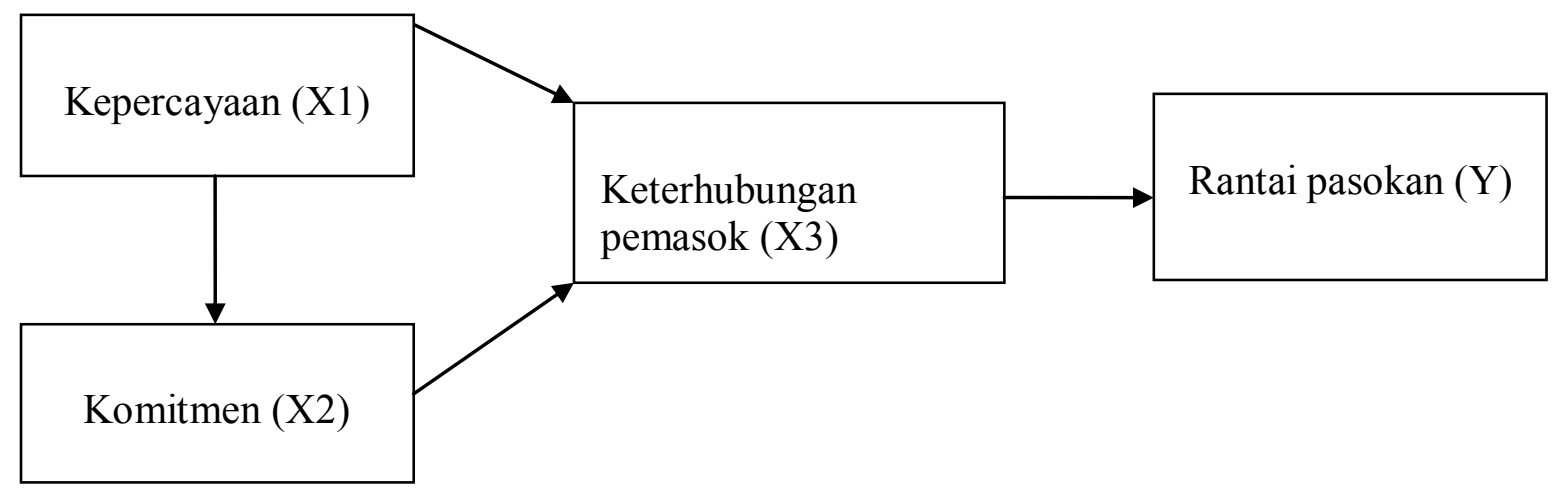

\section{METODE PENELITIAN}

Desain penelitian yang digunakan dalam penelitian ini menggunakan metode eksplanatif korelasional untuk membandingkan suatu variabel (objek penelitian), antara berbeda atau waktu yang berbeda dalam menemukan sebab akibatnya. Teknik pemilihan sampel yang digunakan dalam penelitian ini adalah teknik non proabability sampling agar sampel yang sudah digunakan tidak digunakan kembali. Populasi yang diambil dalam penelitian ini adalah para pemilik toko kelontong di DKI Jakarta, jumlah sampel yang digunakan pada penelitian ini berjumlah 164 sampel dengan periode pengambilan data yang berlangsung selama tiga bulan dimulai dari bulan November 2016 sampai bulan Februari 2017.

Kuesioner yang diberikan terdiri atas 13 pertanyaan yang mewakili indikator-indikator masing-masing peubah yaitu kepercayaan, komitmen, keterhubungan pemasok, dan rantai pasokan. Ukuran penilaian menggunakan skala likert dari,1 (sangat tidak puas), 2 (tidak puas), 3 (netral), 4 (puas) dan 5 (sangat puas). Untuk memperoleh data yang menjadi dasar analisis, maka sebelumnya dilakukan pengumpulan data dengan cara menyebarkan kuesioner dengan skala Likert kepada pemilik toko kelontong di DKI Jakarta. Data yang sudah dikumpulkan akan diolah menggunakan IBM SPSS AMOS 24.

\section{HASIL DAN PEMBAHASAN \\ Profil Responden}

Tabel 1

\section{Profil Responden berdasarkan wilayah}

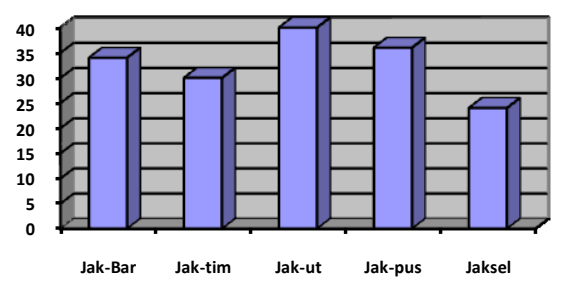

Sumber : Peneliti 2017 


\section{$\mathrm{N}=164$ responden}

Terbanyak responden berasal dari wilayah Jakarta Utara sebanyak 40 sampel dan Jakarta Pusat sebanyak 36.

Tabel 2

Profil Responden berdasarkan Lama Usaha

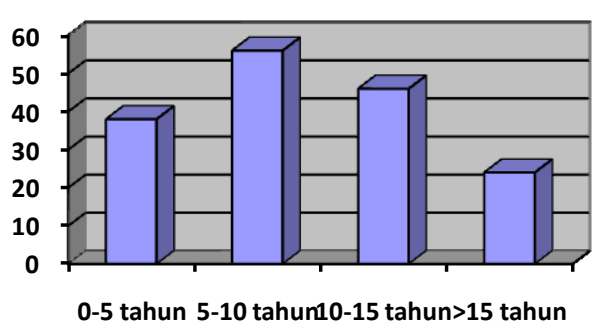

Sumber : Peneliti 2017

$\mathrm{N}=164$ responden
Terbanyak responden memiliki lama usaha 5-10 tahun sebanyak 56 sampel, kemudian 10-15 tahun sebanyak 46 sampel.

Uji Model Goodness of-fit Model

Pengujian menggunakan model SEM dilakukan secara bertahap. jika belum diperoleh model yang tepat (fit), maka model yang diajukan semula perlu direvisi. Perlunya revisi dari model SEM muncul dari adanya masalah yang muncul dari analisis. Apabila masalah-masalah tersebut muncul Haryono et al (2012) Analisis hasil pengolahan data pada tahap full model SEM dilakukan dengan melakukan uji kesesuaian dan uji statistic. Hasil uji goodness-of-fit model dijelaskan pada Gambar

\section{Gambar 4}

Uji Model Measurement

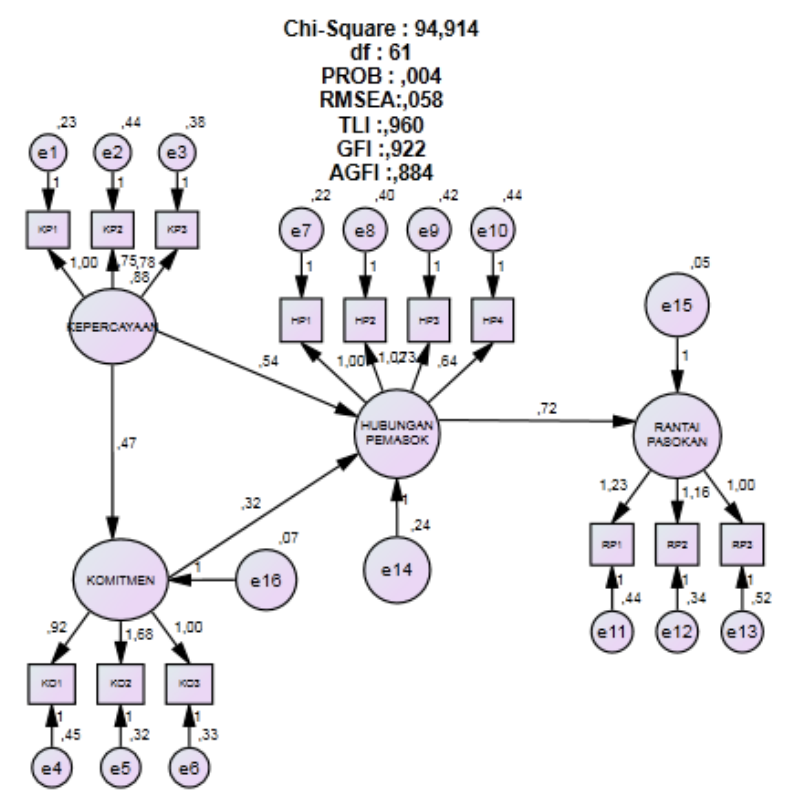

Sumber : IBM AMOS 24 


\section{$\mathrm{n}=164$ responden}

Dari gambar 4 di atas dapat dilihat bahwa model yang digunakan dapat diterima. Nilai CMIN 1,556 lebih besar dari 0,05 menunjukkan model dianggap fit dengan data yang ada, RMSEA berada pada rentang yang diharapkan 0,058<0,08.

Kemudian pengujian dilanjutkan dengan pengujian selanjutnya yang akan disajikan pada tabel di bawah ini.

\section{Tabel 3}

Goodness of Fit Index (GFI) dan

Adjusted Goodness of Fit Index (AGFI)

\section{Sumber : IBM AMOS 24}

$$
(n=164 \text { responden) }
$$

\begin{tabular}{|l|cccc|}
\hline Model & RMR & GFI & AGFI & PGFI \\
\hline $\begin{array}{l}\text { Default } \\
\text { model }\end{array}$ &, 035 &, 922 &, 884 &, 618 \\
$\begin{array}{l}\text { Saturated } \\
\text { model }\end{array}$ &, 000 & 1,000 & & \\
$\begin{array}{l}\text { Independence } \\
\text { model }\end{array}$ &, 396 &, 278 &, 158 &, 238 \\
\hline
\end{tabular}

Dari tabel 3 di atas dapat dilihat bahwa nilai GFI sudah baik $(>0,90)$, dan AGFI masih berada pada tahap marjinal.
Tabel 4

Baseline Comparisons

Sumber : IBM AMOS 24

( $n=164$ responden)

\begin{tabular}{|l|rrrrr|}
\hline Model & $\begin{array}{r}\text { NFI } \\
\text { Delta1 }\end{array}$ & $\begin{array}{r}\text { RFI } \\
\text { rho1 }\end{array}$ & $\begin{array}{r}\text { IFI } \\
\text { Delta2 }\end{array}$ & $\begin{array}{r}\text { TLI } \\
\text { rho2 }\end{array}$ & CFI \\
\hline $\begin{array}{l}\text { Default } \\
\text { model } \\
\begin{array}{l}\text { Saturated } \\
\text { model }\end{array}\end{array}$ &, 918 &, 895 &, 969 &, 960 &, 968 \\
$\begin{array}{l}\text { Independence } \\
\text { model }\end{array}$ & 1,000 & & 1,000 & & 1,000 \\
\hline
\end{tabular}

Pada tabel 4 untuk dasar incremental (baseline comparison) nilai NFI $(0,918)$ dan TLI $(0,960)$ di atas 0,9 yang mendekati angka 1 menunjukkan model telah fit

Tabel 5

Aikake Information Criterion (AIC) Sumber : IBM AMOS 24 $(n=164$ responden)

\begin{tabular}{|l|rrrr|}
\hline Model & AIC & BCC & BIC & CAIC \\
\hline $\begin{array}{l}\text { Default } \\
\text { model }\end{array}$ & 154,914 & 160,552 & 247,910 & 277,910 \\
$\begin{array}{l}\text { Saturated } \\
\text { model }\end{array}$ & 182,000 & 199,101 & 464,088 & 555,088 \\
$\begin{array}{l}\text { Independence } \\
\text { model }\end{array}$ & 1178,211 & 1180,654 & 1218,509 & 1231,509 \\
\hline
\end{tabular}

Pada tabel 5 nilai AIC pun sudah baik karena AIC default model lebih rendah dari nilai satuarated model dan independence model 
Tabel 6

Expected Cross Validation Index

(ECVI)

Sumber : IBM AMOS 24

$(n=164$ responden)

\begin{tabular}{|l|rrrr|}
\hline Model & ECVI & $\begin{array}{r}\text { LO } \\
90\end{array}$ & $\begin{array}{r}\text { HI } \\
90\end{array}$ & MECVI \\
\hline $\begin{array}{l}\text { Default } \\
\text { model }\end{array}$ &, 950 &, 812 & 1,137 &, 985 \\
$\begin{array}{l}\text { Saturated } \\
\text { model }\end{array}$ & 1,117 & 1,117 & 1,117 & 1,221 \\
$\begin{array}{l}\text { Independence } \\
\text { model }\end{array}$ & 7,228 & 6,577 & 7,925 & 7,243 \\
\hline
\end{tabular}

Pada tabel 6 Nilai ECVI default model sudah bagus karena lebih rendah dari nilai satuarated model dan independence model.
Tabel 7

HOELTER

Sumber : IBM AMOS 24

\begin{tabular}{|l|rr|}
\multicolumn{4}{|c}{$(\mathbf{n}=\mathbf{1 6 4}$ responden $)$} \\
Model & HOELTE & HOELTE \\
& $\mathrm{R}$ & $\mathrm{R}$ \\
& .05 & .01 \\
\hline $\begin{array}{l}\text { Default } \\
\text { model }\end{array}$ & 138 & 154 \\
$\begin{array}{l}\text { Independen } \\
\text { ce model }\end{array}$ & 15 & 16 \\
\hline
\end{tabular}

Pada tabel 5.7 Nilai HOETLER (138) juga sudah baik karena di bawah cutoff 200. Dengan demikian, menurut Singgih Santoso (2012) hasil Chi Square disukung oleh alat-alat statistik yang lain, sehingga dapat dikatakan model di atas telah fit

\section{Uji Measurement Model}

Sesudah menguji model sudah fit, maka langkah selanjutnya adalah menguji ketepatan peubah manifest dapat menjelaskan variabel laten yang ada

Tabel 8

Regression Weights: (Group number 1 - Default model)

Sumber : IBM AMOS 24

$(n=164$ responden)

\begin{tabular}{|c|c|c|c|c|c|c|c|}
\hline & & & Estimate & S.E. & C.R. & $\mathrm{P}$ & Label \\
\hline KP1 & $<---$ & KEPERCAYAAN & 1,000 & & & & \\
\hline KP2 & $<---$ & KEPERCAYAAN &, 755 & ,070 & 10,792 & $* * *$ & par 1 \\
\hline KP3 & $<---$ & KEPERCAYAAN & ,784 & ,068 & 11,557 & $* * *$ & par_2 \\
\hline KO3 & $<---$ & KOMITMEN & 1,000 & & & & \\
\hline $\mathrm{KO} 2$ & $<---$ & KOMITMEN & 1,680 & 201 & 8,338 & $* * *$ & par_3 \\
\hline KO1 & $<---$ & KOMITMEN & ,924 & ,144 & 6,416 & $* * *$ & par 4 \\
\hline HP1 & $<---$ & HUBUNGAN_PEMASOK & 1,000 & & & & \\
\hline HP2 & $<---$ & HUBUNGAN_PEMASOK & 1,015 & ,085 & 11,959 & $* * *$ & par_5 \\
\hline HP3 & $<---$ & HUBUNGAN_PEMASOK &, 727 &, 076 & 9,501 & $* * *$ & par_6 \\
\hline HP4 & $<---$ & HUBUNGAN_PEMASOK & ,639 & ,076 & 8,375 & $* * *$ & par_7 \\
\hline RP3 & $<---$ & RANTAI_PASOKAN & 1,000 & & & & \\
\hline RP2 & $<---$ & RANTAI_PASOKAN & 1,157 & , 140 & 8,276 & $* * *$ & par_8 \\
\hline RP1 & $<---$ & RANTAI_PASOKAN & 1,230 & ,148 & 8,317 & $* * *$ & par_9 \\
\hline
\end{tabular}




\section{Uji Model Struktural}

Uji Struktural Model merupakan tahap lanjutan setelah Uji Measurement Model. Pada tahap ini peneliti akan menguji structural parameter estimate, yakni hubungan di antara konstruk atau

Tabel 9

Regression Weights: (Group number 1 - Default model)

Sumber : IBM AMOS 24

$(n=164$ responden)

\begin{tabular}{|c|c|c|c|c|c|c|c|}
\hline & & & Estimate & S.E. & C.R. & $\mathrm{P}$ & Label \\
\hline KOMITMEN & $<--$ & KEPERCAYAAN & ,465 & ,059 & 7,820 & $* * *$ & par_13 \\
\hline $\begin{array}{l}\text { HUBUNGAN_ } \\
\text { PEMASOK }\end{array}$ & $<---$ & KEPERCAYAAN & ,536 & ,160 & 3,350 & $* * *$ & par_10 \\
\hline $\begin{array}{l}\text { HUBUNGAN } \\
\text { PEMASOK }\end{array}$ & $<---$ & KOMITMEN &, 320 & ,297 & 1,077 & ,282 & par_11 \\
\hline $\begin{array}{l}\text { RANTAI } \\
\text { PASOKAN }\end{array}$ & $<---$ & $\begin{array}{l}\text { HUBUNGAN_PEMAS } \\
\text { OK }\end{array}$ &, 724 & ,082 & 8,822 & $* * *$ & par_12 \\
\hline
\end{tabular}

Pada tabel 9 dapat dilihat bahwa variabel kepercayaan mempunyai korelasi lemah positif dan signifikan terhadap komitmen sebesar 0,465, variabel kepercayaan mempunyai korelasi kuat positif dan signifikan terhadap hubungan peamasok sebesar 0,536, variabel komitmen mempunyai korelasi lemah positif namun tidak signifikan terhadap hubungan peamasok sebesar 0,320, dan variabel keterhubungan pemasok mempunyai variabel independen-dependen yang ada dalam struktural model, untuk menguji hubungan antar konsruk tersebut akan disajikan pada tabel9 . 


\section{Tabel 10}

Assessment of normality (Group number 1)

Sumber : IBM AMOS 24

\begin{tabular}{|l|rrrrrr|}
\hline \multicolumn{7}{|c|}{ (n= 164 responden) } \\
\hline Variable & min & Max & Skew & c.r. & Kurtosis & c.r. \\
RP1 & 2,000 & 5,000 &,- 501 & $-2,619$ &,- 903 & $-2,361$ \\
RP3 & 2,000 & 5,000 &,- 570 & $-2,981$ &,- 544 & $-1,422$ \\
HP4 & 2,000 & 5,000 &,- 398 & $-2,079$ &,- 760 & $-1,987$ \\
HP3 & 2,000 & 5,000 &,- 096 &,- 503 &,- 785 & $-2,052$ \\
HP2 & 2,000 & 5,000 &,- 106 &,- 552 & $-1,014$ & $-2,651$ \\
HP1 & 2,000 & 5,000 &,- 437 & $-2,286$ & $-1,071$ & $-2,798$ \\
KO1 & 2,000 & 5,000 &,- 599 & $-3,132$ &,- 831 & $-2,172$ \\
KO2 & 2,000 & 5,000 &,- 320 & $-1,671$ &,- 437 & $-1,143$ \\
KO3 & 2,000 & 5,000 &,- 347 & $-1,815$ & $-1,040$ & $-2,719$ \\
KP3 & 2,000 & 5,000 &,- 252 & $-1,318$ &,- 279 &,- 729 \\
KP2 & 2,000 & 5,000 &,- 331 & $-1,732$ &,- 827 & $-2,161$ \\
KP1 & 2,000 & 5,000 &,- 215 & $-1,126$ &,- 946 & $-2,472$ \\
Multivariate & 2,000 & 5,000 &,- 539 & $-2,819$ &,- 928 & $-2,426$ \\
& & & & & 19,526 & 6,331 \\
\hline
\end{tabular}

Berdasarkan tabel 5.12, maka data tersebut dapat dikatakan sudah normal karena nilai cr secara univariate berada pada $+-2,58$

\section{PEMBAHASAN}

Penelitian ini menunjukan bahwa adanya pengaruh dari kepercayaan dan komitmen dari hubungan pemasok terhadap rantai pasokan.

Hasil hipotesis 1, menjelasakan bahwa terdapat pengaruh kuat positif dan signifikan pada variabel kepercayaan terhadap keterhubungan pemasok sebesar 54\% dengan tingkat signifikansi dibawah 0,05 dan nilai cr diatas 1,96. Hasil ini mendukung penelitian Ganesan (1994) yang membuktikan bahwa kredibilitas akan mempengaruhi orientasi pembeli untuk menjalin hubungan jangka panjang.
Hasil hipotesis 2, menjelasakan bahwa Terdapat pengaruh lemah positif dan tidak signifikan pada variabel komitmen terhadap keterhubungan pemasok sebesar 32\% dengan tingkat signifikansi dibawah 0,05 dan nilai cr dibawah 1,96.

Hasil hipotesis 3, menjelasakan bahwa Terdapat pengaruh lemah positif dan signifikan pada variabel kepercayaan terhadap komitmen sebesar $47 \%$ dengan tingkat signifikansi dibawah 0,05 dan nilai cr diatas 1,96 .

Hasil hipotesis 4, menjelasakan bahwa Terdapat pengaruh kuat positif dan signifikan pada variabel keterhubungan 
pemasok terhadap rantai pasokan sebesar $72 \%$ dengan tingkat signifikansi dibawah 0,05 dan nilai $\mathrm{cr}$ diatas 1,96 .

Hal ini sejalan dengan penelitian terdahulu pada penelitian Riset Geyskens et al. (1999). Studi tentang kepercayaan pada pemasok merujuk pada Cempaka dan Yoestini (2003). Studi Nursatyo (2003) pada penelitian ini menggaris bahwahi studi hubungan jangka panjang dengan pemasok. kepercayaan, dan hubungan jangka panjang pemasok dengan kinerja rantai pasok pada penyalur merujuk pada riset empiris pada penelitian Garbarino dan Johnson (1999); Ganesa (1994).

\section{PENUTUP}

\section{Simpulan}

Hasil dari penelitian ini menunjukan bahwa rantai pasokan secara positif dan signifikan dipengaruhi oleh kepercayaan dan komitmen dari pemilik toko kelontong melalui hubungan dengan pemasok. Oleh karena itu bagi para pemilik toko kelontong sebaiknya memperhatikan beberapa hal seperti; kinerja persediaan, keterpenuhan dan ketanggapan dari rantai pasokan memang membutuhkan peran dan andil yang baik dari pemasok dan pedagang toko kelontong.

\section{Saran}

Bagi pemilik toko kelontong, perlu mempertimbangkan beberapa hal, seperti pemenuhan barang, program pengembalian barang rusak agar manajemen rantai pasokan dapat terjaga dengan baik

Hal lainya yang perlu diperhatikan bagi pemilik toko kelontong untuk mendukung kinerja rantai pasokan, antara lain; melakukan kesepakatan dalam pencapaian target penjualan, promo spesial hari besar, dan kejelasan dalam hal retur barang agar rantai pasokan dapat berjalan dengan baik sehingga dapat mengurai biaya penyimpanan,biaya kerusakaan barang yaang membantu dalam rantai pasokan

Pada penelitian ini terdapat beberapa kendala bagi peneliti dalam meneliti, antara lain sampel yang di gunakan Jakarta masih bersifat random convinience (kemudahan bagi peneliti). Hal lain yang dapat dikembangkan adalah mengategorikan secara spesifik toko kelontong besar, menengah, kecil. Seperti agen, warung karena pada penelitian ini peneliti menggabungkan jenis toko tersebut. 


\section{DAFTAR PUSTAKA}

\section{BUKU}

Bollen, K dan Lennox, R. 1991. "Conventional Wisdom on Measurement: A Structural Equation Perspectives. Psychological Bulletin. 110 (2), pp. 305- 314. . 2007. Retail Management :A Strategy Approach, Tenth Edition New Jersey : Pearson prentice Hall.

Bungin, Burhan, 2010. Metode Penelitian Kuantitatif. Jakarta: Kencana.

Cempaka, Diah Arum dan Yoestini, 2003. Studi Mengenai pengembangan Hubungan Jangka Perusahaan dan Tenaga kerja

Chin, W 1998 The Partial Least Square Approach for Structural Equation Modeling. Cleveland.Ohio.

Chopra, S. and Meindl, P., 2007, Supply Chain Management: Strategy, Planning and Operasion, 2nd or 3rd Edition, New Jersey: Pearson Prentice Hall.

Cooper, D.R \& P.S. Schindler. 2006. Business Research Methods, 9th Edition, McGraw-Hill Companies, Inc., New York.

Ferdinand, A. 2006. Metode Penelitian Manajemen. Semarang. BP UNDIP

Ghozali, Imam. 2009. Aplikasi Analisis Multivariate Dengan Program SPSS. Cetakan Keempat. Semarang: Badan Penerbit Universitas Diponegoro. . 2011. Aplikasi Analisis Multivariate Dengan Program IBM SPSS19 (edisi kelima). Semarang. Universitas Diponegoro.

Hubeis, Musa. 2009. Prospek Usaha Kecil Dalam Wadah Inkubator Bisnis. Bogor. Ghalia.

J. Supranto, M.A. 2002. Metode Peramalan Kuantitatif untuk Perencanaan Ekonomi dan Bisnis, Jakarta : Rineka Cipta. Makridakis, Spyros
Tambunan, Tulus T.H. 2004. Globalisasi dan Perdagangan Internasional. Jakarta: Ghalia Indonesia.

Tanehaus,M., Vinci, Chatelin, Y.M,. dan Carlo,L 2005. PLS Path Modeling. Computational Statistic and data analysis.

Simchi-Levi et. Al, 2000. Designing and Managing the Supply Chain: Concepts, Strategies and Case Studies. McGrawHill International Edition, Singapore.

Santoso.,2012. "Analisis SEM menggunakan AMOS". PT Elex Media Komputerindo Sugiyono, 2010. Model penelitian Kuantitatif Kualitatif \& RND. Bandung : Alfabeta

\section{JURNAL}

Ambrose Eamonn, Marshall Donna, Brian Lynch 2008 International Journal of Operations and Production Management, 28 (4): 360-379

Anderson, Erin dan Barton Weitz, 1992, "The Use of Pledges to Build and Sustain Commitment in Distribution Channels", Journal of Marketing Research, Vol. XXIX, February, pp. 18-34

Anderson, James C. dan James A. Narus, 1990, "A Model of Distributor Firm and Manufacturer Firm Working Partnerships"

Bollen, K.A., R. Lennox, 1991. "Conventional wisdom on measurement - a structural equation perspective", Psychological Bulletin 110 (2). 305-314.

Chatterjee, S. C., Hyvonen, S. \& Anderson, E. 1995. "Concentrated vs. balanced sourcing: An examination of retailer purchasing decisions in closed market". Journal of Retailing, Vol. 71 No. 1

Doney, Patricia M., dan Joseph P. Cannon, 1997, "An Examination of the Nature of Trust in Buyer-Seller Relationship", Journal of Retailing Vol 40 
Ganesan, Shankar, 1994, "Determinants of LongTerm Orientation in Buyer-Seller Relationship", Journal of Marketing, Vol. 58, April, pp. 1-19

Garbarino, Ellen, dan Mark S. Johnson, 1999, "The Different Roles of Satisfaction, Trust, and Commitment in Customer Relationship", ", Journal of Marketing, Vol. 32

Kwon, Ik- Whan, G and Taewon Suh, (2004) . "Factor affecting the level of trust and commitment in supply chain relationship: : A status Review. European Journal of Social Sience. Vol 23 No3 :403 -501

Lambert, Douglas, et al. "The International Journal of Logistic Management". Vol 9.No 2

Mutiara I Dewi, 2013, "Implementasi Kebijakan Perencanaan Penataan Toko Modern Berjaringan Nasional di Kabupaten Sleman dalam Kajian Ekonomi Politik". No 523/BOPTN/UN.34.21/2013

Noordewier, John, \& Nevin. 1990. "Performance Outcomes of Purchasing Arrangements in Industrial BuyerVendor Relationships". Journal of Marketing. 54 (4): 80-93.

Robert M., dan Shelby D. Hunt, 1994, “The Commitment-Trust Theory of Relationship Marketing", Journal of Marketing, Vol. 58, July, pp. 20-38

Praharsi, Y., Wee, H., Sukwadi, R. \& Padilan, M. V. 2014. "Smallindependent retailers vs. organized retailers: An empirical study in Indonesian economics of service industries". Journal of Retailing and Consumer Services, Vol. 21 No. 2

Ramdas,K and Speakman R,E. 2000. "Chain or shackles : Understanding what Drives Supply Chain Performance". Interfaces vol 30 (4):3-21

Simatupang T.M. dan Sridharan R. 2005. “An integrative framework for supply chain collaboration". International Journal of Logistic Management 13(1):15-30
Sheth, 1994, "An Experimental Approach to Investigating Satisfaction and Continuity in Marketing Alliances", European Journal of Marketing, Vol. 29 , No. 4, pp. 6-23

Smeltzer, L. 1997. "The Meaning and Origin of Trust in Buyer-Supplier Relationship". International Journal of Purchasing and Materials Management Vol 33 No 1 p 40-8.

Wiboonponse, Aree dan Songsak Sriboonchitta. 2006. "Securing Small Producer Participation in Restructured National and Regional Agri-Food Systems" : The Case of Thailand. Regoverning Markets [online]

Wu, I., Chuang, C. \& Hsu, C. (2014). "Information sharing and collaborative behaviors in enabling supply chain performance: A social exchange perspective". International Journal of Production Economics, Vol. 14 